\title{
Erratum to: Antibody-mediated neutralization of myelin-associated EphrinB3 accelerates CNS remyelination
}

\author{
Yasir A. Syed ${ }^{1,3} \cdot$ Chao Zhao $^{1}$ - Don Mahad $^{2}$ - Wiebke Möbius ${ }^{3} \cdot$ Friedrich Altmann $^{4} \cdot$ Franziska Foss $^{5}$. \\ G. A. González ${ }^{10}$ - Aycan Sentürk ${ }^{5}$ Amparo Acker-Palmer ${ }^{5}$ - Gert Lubec ${ }^{6,9} \cdot$ Kathryn Lilley $^{7}$ • \\ Robin J. M. Franklin ${ }^{1}$ Klaus-A. Nave ${ }^{3}$ Mark R. N. Kotter ${ }^{1,3,8}$
}

Published online: 9 May 2016

(C) Springer-Verlag Berlin Heidelberg 2016

\section{Erratum to: Acta Neuropathol (2016) 131:281-298 DOI 10.1007/s00401-015-1521-1}

The original article was published with the incorrect author group. The correct author group is provided below:

Yasir A. Syed • Chao Zhao • Don Mahad • Wiebke Möbius • Friedrich Altmann • Franziska Foss • G. A. González • Aycan Sentürk • Amparo Acker-Palmer $\bullet$ Gert Lubec $\bullet$ Kathryn Lilley $\bullet$ Robin J. M. Franklin • Klaus-A. Nave • Mark R. N. Kotter

The affiliation for the new author, G. A. González is as follows:

Anne McLaren Laboratory for Regenerative Medicine, and Department of Clinical Neuroscience, University of Cambridge, Cambridge, UK.

The online version of the original article can be found under doi:10.1007/s00401-015-1521-1.

Mark R. N. Kotter

mrk25@cam.ac.uk

1 Wellcome Trust and MRC Cambridge Stem Cell Institute, Department of Clinical Neurosciences, Anne McLaren Laboratory, University of Cambridge, Cambridge CB2 0SZ, UK

2 Centre for Neuroregeneration, Chancellor's Building, 49 Little France Crescent, Edinburgh EH16 4SB, UK

3 Department of Neurogenetics, Max Planck Institute for Experimental Medicine, 37075 Goettingen, Germany

4 Department of Chemistry, University of Natural Resource and Life Sciences, Muthgasse 18, 1190 Vienna, Austria

5 Frankfurt Institute for Molecular Life Sciences and Institute of Cell Biology and Neuroscience, Goethe University Frankfurt, Max-von-Laue-Str. 9, 60438 Frankfurt am Main, Germany
6 Department of Pediatrics, Medical University Vienna, Waehringer Guertel 18-20, 1090 Vienna, Austria

7 Cambridge Centre for Proteomics, Department of Biochemistry, University of Cambridge, Tennis Court Road, Cambridge CB2 1QW, UK

8 Universitätsmedizin Göttingen, Universitätsklinik für Neurochirurgie, Robert-Koch-Straße 40, 37075 Göttingen, Germany

9 Department of Pharmaceutical Chemistry, University of Vienna, Althanstrasse 4, 1090 Vienna, Austria

10 Department of Clinical Neuroscience, Anne McLaren Laboratory for Regenerative Medicine, University of Cambridge, Cambridge, UK 